\title{
Sweat Analysis and Cystic Fibrosis : A Golden Handshake
}

\author{
Manzoor Raina, M.Sc., ${ }^{\dagger} \dagger$, Mosin S Khan, Ph.D., $†$, Abdul H Raina, M.D., ${ }^{2}$ Mudassir Makhdoomi, M.Sc., \\ Syed Mudassar, Ph.D.' \\ ' Department of Clinical Biochemistry, Sher-i-Kashmir Institute of Medical Sciences, Soura, Srinagar. \\ ${ }^{2}$ Department of Internal Medicine, Sher-i-Kashmir Institute of Medical Sciences, Soura, Srinagar. \\ ${ }^{\dagger}$ Both authors have contributed equally.
}

\section{A B S T RA C T}

Cystic fibrosis (CF) is one of the most lethal, autosomal recessive, monogenic disorder that presents as a multisystem disease with significant morbidity and mortality in all parts of the world caused due to an abnormal transport of chloride ions across the apical membranes of epithelial cells. This autosomal recessive genetic disorder is caused by mutations of the CF transmembrane conductance regulator (CFTR) gene on chromosome $7 \mathrm{q} 31.2$. $^{1}$ The CFTR gene encodes the CFTR chloride-ion channel that is an essential component of epithelial ion transport systems in many organs, including the lungs, pancreas, intestinal tract, hepatobilliary tract, vas deferens and sweat glands. Cystic fibrosis (CF) affects exocrine gland function that involves multiple organ systems. Classical CF is characterized by progressive lung disease, pancreatic dysfunction, elevated sweat chloride electrolyte, meconium ileus and male infertility and associated complications in untreated patients. ${ }^{2}$ JMS 2015; 18(2):134-137

Keywords: Cystic fibrosis, Analysis, Sweat.

\section{INTRODUCTION}

The sweat test, using the method of pilocarpine iontophoresis and quantitative analysis of sweat chlorides according to Gibson and Cooke method, has been the gold standard for almost a half century. ${ }^{3}$ Approximately in $98 \%$ patients with $\mathrm{CF}$, sweat chloride value remains elevated. ${ }^{4}$ The diagnosis of CF could easily be made in the majority of cases based on typical clinical features and abnormal sweat chloride values.

Cystic fibrosis was thought to be extremely rare in India and was first reported in 1968. ${ }^{5,6}$ However published reports, reviews and comments indicate that $\mathrm{CF}$ is probably far more common in people of Indian origin than previously thought but is under diagnosed or missed in the majority of cases. $^{\top}$

\section{Correspondence}

Dr. Syed Mudassar, Ph.D.

Professor and Head, Department of Clinical Biochemistry, SKIMS, Soura, Srinagar, Kashmir, India-190011

Email:syed.mudassar@skims.ac.in, mosin.khan@skims.ac.in
Only few studies have undergone from the valley of Kashmir on cystic fibrosis and sweat chloride analysis. Tasaduq et al. 2011 did an observational study to describe the clinical profile, and delays in diagnosing $\mathrm{CF}$ in Kashmir, India. They subjected 150 suspected patients to pilocarpine iontophoresis. CF was diagnosed in three $(0.8 \%)$ with 6.5 years as Median age of presentation. ${ }^{8}$

Masarat et al. 2013 screened one hundred consecutive children patients presenting with one or more phenotypic features suggestive of $\mathrm{CF}$ by quantitative sweat chloride testing. Out the 100 patients, 18 were diagnosed to have $\mathrm{CF}$ at a mean age of 5.0 years. Positive sweat chloride ( $>60$ $\mathrm{meq} / \mathrm{L})$ was seen in $14(14 \%)$ patients and $4(4 \%)$ patients had equivocal (40-60 meq/L) value on two different occasions. ${ }^{9}$

The number of CF patients in Kashmir valley is very large compared to the expected values as large number of patients suspected for Cystic Fibrosis attend Sher-i-Kashmir Institute of Medical Sciences, GB pant and associated 
hospitals of Srinagar. In view of the large number of patients suspected for CF across the valley there was a dire need for establishment of sweat testing in the department of Clinical biochemistry SKIMS, Srinagar as it is the only tertiary care hospital in Kashmir region. Before the establishment of this routine diagnostic facility at SKIMS, Srinagar, sweat testing was done as a research parameter which was a discontinuous process and most of the patients had to go out of valley for doing a sweat test resulting in wastage of money and resources. Our department has introduced sweat testing for the first time in Kashmir valley as a diagnostic test for those who are suffering from this dreadful disease.

\section{METHODOLOGY}

The test was done by a validated method and equipment.10 Procedure involves Sweat stimulation, Sweat collection and Quantitative sweat measurement for chloride. Sweat stimulation and Sweat collection is based on the Gibson and Cooks methodology involving pilocarpine iontophoresis. ${ }^{3}$ The quantitative estimation of chloride was done by Schales and Schales method with some modifications. 11 A positive test, sweat chloride concentration $\geq 60 \mathrm{mmol} / \mathrm{L}$ was confirmed by repeat test. Patients with borderline values were put on follow up. A negative test was repeated only under strong clinical suspension.

\section{RESULT}

We have started giving sweat chloride levels since October 2013 and since last one and a half years (up to April 2015) we subjected one hundred and eighty three $(n=183)$ high risk patients to pilocarpine iontophoresis followed by quantitative estimation of sweat chloride levels (Figure 1)

Patients were referred to our laboratory not only form SKIMS but from the GB pant and associated hospitals of the valley (Figure 2). In addition, the patients came from almost every district of the valley (Figure 3) which justifies the effective outreach of this important sweat analysis for chloride levels. One patient was even from Kargil region and two from Ramban district of Jammu region.

Among one hundred eighty two $(n=182)$ patients enrolled for sweat testing $41(23 \%)$ were having elevated sweat

chloride levels, 09 (5\%) were Borderline and 132 (72\%) were having normal sweat chloride levels (Figure 4) which depicts the alarming scenario of Cystic fibrosis in Kashmir valley. The mean age at presentation was 4.0 years (48 months) which is in almost in tune with the study done by Kabra et al. (54 months) involving various states of India ${ }^{12}$. Figure 5 shows the month wise distribution of positive cases. Maximum number of positive cases were reported from Baramulla, Srinagar and Anantnag (Figure 6). Greater percentage of cystic fibrosis patients were attending the department of Pediatrics, SKIMS with respect to other hospitals (Figure 7).

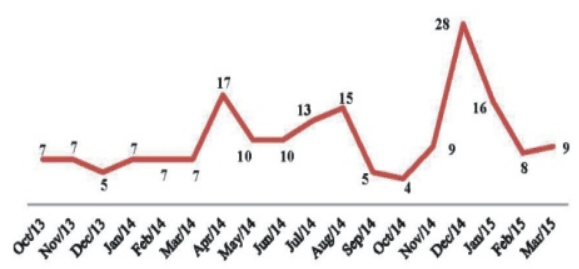

Figure 1: Graph showing the number of patients enrolled for sweat testing monthly

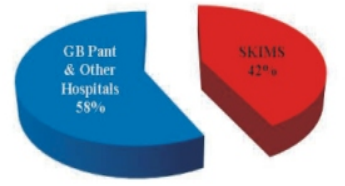

Figure 2: Pie diagram depicting the number of patients referred from various hospitals for sweat testing

- KUPWARA "BARAMULLA

"

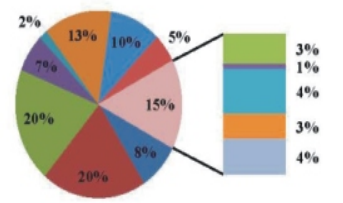

Figure 3: Distribution of high risk patients among various districts of valley including Kargil and Ramban

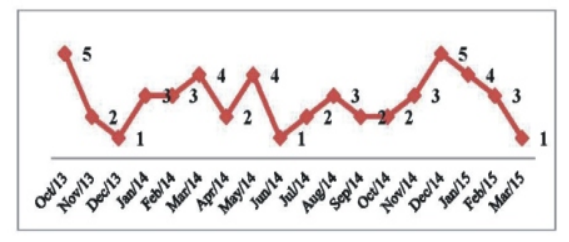

Figure 5: Month wise distribution of positive cases 


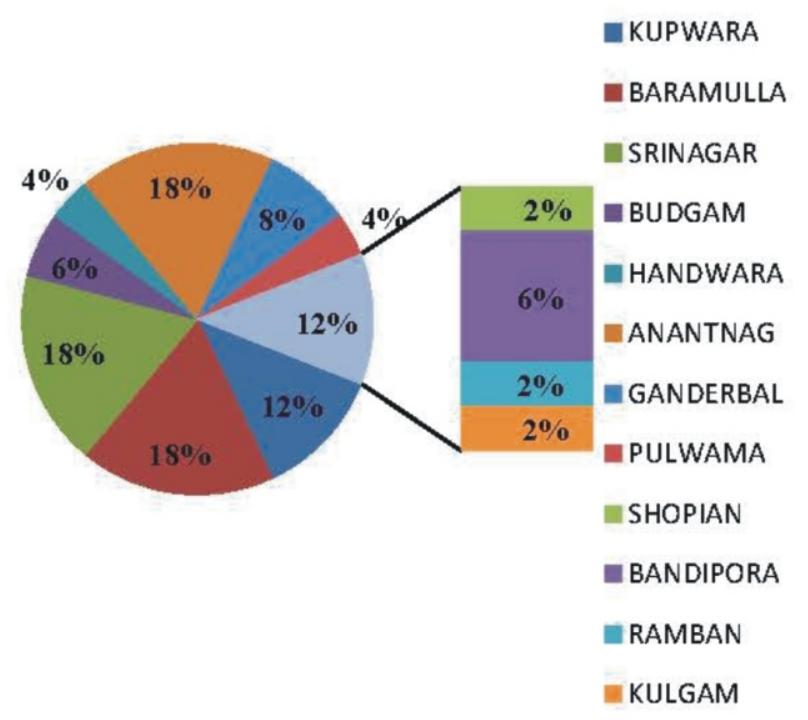

Figure 6: District wise distribution of Positive cases

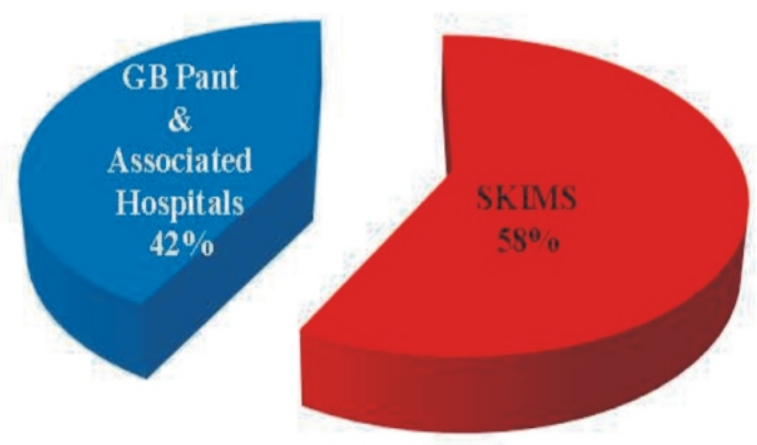

\section{Figure 7: Referral hospitals of Cystic fibrosis patients}

\section{CONCLUSION}

By introducing the sweat testing facility the early and accurate diagnosis of $\mathrm{CF}$ has become possible which has led to the observation that Kashmir valley is perhaps the high incidence zone for CF. As the situation is quite alarming in the valley there is a high need of "State Reference
Laboratory for Sweat Analysis" at SKIMS, Srinagar for better, early and prompt diagnosis of Cystic fibrosis.

\section{REFERENCES}

1. Welsh MJ, Ramsy BW, Accurso F and Cutting GR. Cystic fibrosis. In Scriver CR, Beaudet AL, Sly WS, Valle D (Ed.), The metabolic and molecular basis of inherited disease, 8th ed., New York, NY: McGrawHill, 2001:51215188.

2. Dequeker E, Cuppens H, Dodge J, Estivill X, Goossens M, Pignatti PR, et al. Recommendations for quality improvement in genetic testing for cystic fibrosis. European concerted action on cystic fibrosis. Eur J Hum Genet. 2000;8:S224.

3. Gibson L and Cooke R. A test for concentration of electrolytes in sweat in cystic fibrosis of the pancreas utilizing pilocarpine by iontophoresis. Pediatrics 1959: 545-549.

4. LeGrys VA. Sweat testing for the diagnosis of cystic fibrosis: practical considerations. J Pediatr 1996; 129:892-7.

5. Bhakoo ON, Kumar R and Walia BN. Mucoviscidosis of lungs. Indian J Pediatr 1968;35:183185.

6. Mehta S, Wadhwa UN, Mehta SK and Chhutani PN. Fibrocystic disease of pancreas in India. Indian Pediatr 1968;5:185191.

7. Kabra SK and Kabra M, Cystic fibrosis in India. Nat Med J India 2003;16:291 293.

8. Tasaduq AM, Mohd A, Kaiser A, Javed C, Rehana B and Javid A. Clinical profile, diagnostic delay, and genetic make-up of cystic fibrosis in Kashmir, India. Lung India 2011;28:97-100.

9. Masarat SK, Mushtaq AB, Syed WA, Imran H, Shivram S. Clinical and Mutation Profile of Children with Cystic Fibrosis in Jammu and Kashmir. Indian Pediatrics 2014;185- 189.

10. Kabra SK, Kabra M, Gera S, Lodha R, Sridevi KN, Chacko S, Mathew J, Shastri S and Ghosh M. An indigenously Developed method for sweat collection and estimation of chloride for diagnosis of Cystic Fibrosis. Indian Pediatrics 2002;39:1039-1043. 
11. Schales O. Schales SS. A simple and accurate method for determination of chloride in biological fluids. $J$. Biol. Chem. 1941:140:879-884.

12. Kabra SK, Kabra M, Lodha R, Shastri S. Ghosh
SM, Pandey RM, Kapil A, Aggarwal G, Kapoor V. Clinical Profile and Frequency of Delta F508 Mutation in Indian Children with Cystic Fibrosis. Indian Pediatrics. 2003; 40: 612-9. 